\title{
MS13-P02 | THE BONE MINERAL IS CARBONATO-HYDRO-APATITE AND IT TRANSFORMS INTO HYDROXYAPATITE BY HEATING (CREMATION) BEYOND $700^{\circ} \mathrm{C}$
}

Greiner, Martina (LMU Munich, Munich, GER); Rodríguez-Navarro, Alejandro (Universidad de Granada, Granada, ESP); Schmahl, Wolfgang (LMU Munich, Munich, GER); Kocsis, Balazs (LMU Munich, Munich, GER); Grupe, Gisela (LMU Munich, PlaneggMartinsried, GER); Mayer, Katrin (LMU Munich, Planegg-Martinsried, GER)

We studied thermal changes in bovine bone mineral between $100^{\circ} \mathrm{C}$ and $1000^{\circ} \mathrm{C}$. Complementary analytical methods were applied to the same unheated and heat treated material to ensure data consistency: quantitative powder X-ray diffraction, Fourier Transform Infrared Spectroscopy (FTIR), and Infrared-coupled Thermogravimetric Analysis (TGA-FTIR). At temperatures from $700{ }^{\circ} \mathrm{C}$ onwards after 30 minutes of heating, a considerable recrystallization reaction from the original bioapatite to hydroxyapatite occurred. No hydroxyl ions are discernible in FTIR spectra of original bone mineral while $\mathrm{CO}_{3}{ }^{2-}$ and $\mathrm{H}_{2} \mathrm{O}$ spectral features are prominently visible. Bovine bone bioapatite thus should be referred to "carbonate-hydro-apatite" rather than hydroxyapatite. The treatment at temperatures $\geq 700^{\circ} \mathrm{C}$ induced a pronounced recrystallization reaction, increasing both the crystallite size and the amount of hydroxyl groups in the apatite lattice. Above $800{ }^{\circ} \mathrm{C}$ buchwaldite, $\mathrm{CaNaPO}_{4}$, is formed from the $\mathrm{Na}$ component of the bone mineral. The changes in the state of the bone mineral are not only dependent on temperature but also on time. The recrystallization reaction strongly accelerates after organic matrix compounds and their residues have been combusted and the apatite grains get into direct contact. 